\title{
Pilot scheme gets go ahead for southern Europe
}

\begin{abstract}
Heidelberg. The council of the European Molecular Biology Laboratory (EMBL) in Heidelberg, Germany, last week approved in principle a radical new scheme to set up regional research groups in the countries of southern Europe.
\end{abstract}

But a decision to increase the EMBL budget sufficiently to accommodate this scheme, as well as supporting the growth of outstations in Cambridge (England) and Grenoble (France), could not be reached. Another meeting has now been arranged for mid-February, when it is hoped that a compromise will be agreed under which the budget will grow by about two per cent in real terms.

Despite the financial uncertainty, Fotis Kafatos, EMBL's new direc- Kafatos: new DG. tor-general, is plan-

ning to press ahead with the launch of a pilot scheme for regional groups. Four groups in Italy, and one in Spain, will be established at selected host institutes during next year.

Each regional group will be led by a young investigator who will preferably be a non-national of the host country, and will also include a technician, a postdoctoral student and a postgraduate student. Such a group will cost EMBL around DM475,000 (US\$150,000) a year for salaries and running costs.

Group leaders will be appointed for five years, and host institutes will be expected to consider that person for a post in their own institute within their fourth year. As such, the scheme offers the only opportunity for a young molecular biologist to work independently across European borders.

Selection of host institutes will begin early in the new year. Sir John Kendrew, EMBL's first director-general, will head the selection team, which will also include heads of the councils and finance committees of EMBL and the European Molecular Biology Organization, also based in Heidelberg.

If this pilot scheme - which will be paid from EMBL's own budget, increased or not - is successful, Kafatos wants to expand it very widely, and very quickly. Provisional plans are to add three additional groups in Italy in 1996 and three more in 1998 "to consolidate the catalytic effects begun in the pilot phase". There are also plans to build up groups in other countries, particularly those in the south of Europe.

Future development, however, depends not only on the proven success of the pilot scheme but also on acquiring funds from external sources. Fund-raising negotiations will begin next year.

The new scheme reflects Kafatos's commitment to improving conditions for science in the southern European states. But he says also that the philosophy of regional groups in different countries was always at the heart of the original EMBL mission, defined in the early 1970 s, to promote molecular biology in member states as well as running a central facility.

The principle of the scheme has the wholehearted support of most staff at the laboratory. But this support is coupled with concerns that it may compete with resources in the main laboratory, which employs around 750 scientists. After years of plenty, central funding has become squeezed in the 1990s. For example, equipment money was cut back by 20 per cent this year.

Some claim that the scheme has political roots. Last year Italy threatened to withdraw from EMBL, claiming that too few Italians held staff scientist positions and that it was therefore not getting 'fair returns'. Spain added its own voice of complaint in September, saying that it was also a victim of this perceived inequality (see Nature 365, 201; 1993).

Despite denials from Kafatos that the choice of Italy as primary site for the pilot scheme was the result of political pressure, this perception remains in the air both inside and outside the laboratory. And Italy has certainly been sufficiently placated to withdraw its threat to pull out.

Kafatos knows that he has taken over EMBL at a difficult time. In a climate of ever-increasing financial constraint in Europe, the central laboratory in Heidelberg has been growing steadily - Kafatos has now made a decision not to push for further growth - and commitments have been made to expanding two outstations.

These are the European Bioinformatics Institute (EBI) in Cambridge, which has managed to acquire most of its support from external funds (see Nature 361, 198; 1993), and the Grenoble outstation, which uses local synchrotron facilities for determining molecular structures.

The European Synchrotron Radiation facility (ESRF) will start operating routinely next year, and the EMBL council believe it must make full use of this new resource by expanding the inadequate laboratories that are already there, and doubling the number of staff from 30 to 60 . France last week committed itself to providing a building, but equipment and running costs are still to be found.

Alison Abbott

\section{Russian foundations under pressure to cooperate}

Moscow. Both financial and logistical pressures are increasing on the various independent foundations established over the past two years to support Russian science. As a result, the long-held dream of the Russian Ministry of Science and Technical Policy of coordinating the activities of these foundations may be coming true.

The largest and most effective body is the International Science Foundation (ISF), established last year by the Hungarian-born financier George Soros. But the foundation is currently unable to meet all the requests deserving support that it has received, and neither can the Russian Foundation for Basic Research (RFBR).

As a result, Vladimir Skulachev, the chairman of the Russian advisory committee for the ISF, told a meeting in Moscow two weeks ago that the foundations have reached an agreement - at present unofficial - to exchange lists of applications that they would like to fund.

If a particular project is present on both lists, said Skulachev, negotiations might take place about how it could be jointly financed. Skulachev estimates that coordinating activities in this way could save the RFBR about one-third of its funds, and the ISF about $\$ 8$ million; such savings would allow significantly more projects to be financed.

The ISF is hoping to reach a similar agreement with INTAL, the aid body being set up through the European Commission in Brussels.

Alexander Goldfarb, director of the ISF's New York office, says that coordinating the activities of the various foundations would not only increase the effectiveness of the way research funds are spent but would also ensure that applications are made to the most appropriate body.

"In many cases we receive applications for projects which deserve a grant, but which we cannot approve since we do not officially finance its topic," says Goldfarb. "We would like to have an agreement with the other foundations that would enable us to forward applications to where they might be approved."

Meanwhile, the shortage of funds at the ISF is becoming increasingly worrying. Although discussions continue on a possible contribution from the US Congress, the search has so far been unsuccessful.

There have, however, been some indications from Boris Saltykov, the Russian minister of science, that the foundation could receive support from his ministry. Skulachev says that it will be "very disappointing" if the foundation has to close down because of the lack of funds. 